\title{
A Survey of School Administrators' Training and Support Related to Evaluating Special Education Teachers
}

\author{
Janelle E. Rodl, San Francisco State University \\ Wes Bonifay, University of Missouri \\ Rebecca A. Cruz, University of California, Berkeley \\ Sarah Manchanda, University of California, Berkeley
}

\begin{abstract}
School administrators are often responsible for observing and evaluating special education teachers. The current study examined the training school administrators received, their needed knowledge and supports, and their confidence in performing job functions related to special education teacher evaluation. A total of 929 school administrators in California completed a 26-item survey in which they reported the training they had received, the usefulness of the training for informing practice, and the confidence they felt in evaluating special educators. Results indicated that most school administrators did not have a background in special education, did not receive training related to evaluating special educators, and felt less confident evaluating special educators than general educators. School administrators, especially those without a background in special education, may need more training and support related to evaluating special education teachers during preparation and in the early years of administration. Training and support should focus on evidenced-based practices for teaching students with disabilities.
\end{abstract}

Keywords: special education teacher evaluation, school administrator preparation, school administrator training, observation instruments, evaluation systems

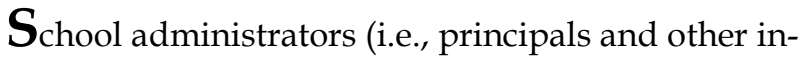
structional leaders) are tasked with directly observing teachers' classroom practice, determining a summary judgment of a teacher's quality and efficacy, and providing feedback to teachers for the purpose of professional growth and development (Goldring et al.,
2015; Grissom, Loeb, \& Master, 2014; Holdheide, Goe, Croft, \& Reschly, 2010). Goldring et al. argue that rigorous, observation-focused evaluation systems are becoming the main driver of principals' human capital decisions (e.g., hiring, evaluating, and rewarding) and that teacher observations may be a more important source of data for principals than value-added or other student growth measures. The Every Student Succeeds Act (ESSA, 2015) allocates resources to states and school districts to support activities related to observations and evaluations. These activities can include developing and disseminating high-quality evaluation tools such as observation rubrics, developing and providing training to principals and other school leaders on how to accurately differentiate performance and provide useful feedback, and providing training on how to use evaluation results to inform personnel decisions.

This paper discusses principals and other school leaders, whom we collectively refer to as school administrators, as individuals responsible for observing and evaluating special education teachers. We focused on special education teachers because questions have arisen regarding whether school administrators, who typically are not licensed or trained in teaching students with disabilities, can reliably and meaningfully observe and evaluate the special education teachers at their school sites (Jones \& Brownell, 2013). As follows, we discuss school administrators' background, training, and preparation related to evaluating special education teachers. We also discuss the implications of each for informing both school administrators' high-stakes decisions (e.g., retention and tenure) and low-stakes decisions (e.g., professional development opportunities). 


\section{Evaluator Background}

Direct observation of classroom practice is the primary form of evaluative data used in many teacher evaluation systems (Goldring et al., 2015; Holdheide, Goe, Croft, \& Reschly, 2010). School administrators are typically responsible for conducting classroom observations of all teachers on their school sites, including special education teachers, but principals and other instructional leaders often lack knowledge regarding evidenced-based instructional strategies recommended for teaching students with disabilities (e.g., explicit and intensive instruction) (Sledge \& Pazey, 2013; Steinbrecher, Fix, Mahal, Serna, \& McKeown, 2015). A lack of knowledge may adversely impact a school administrator's ability to provide an accurate score of a special education teacher's classroom performance (Sledge \& Pazey, 2013), and it may systematically bias ratings of special education teachers (i.e., administrators may systematically score special education teachers higher or lower on certain elements) (Jones \& Brownell, 2013).

Research on school administrators, who may not have a background in teaching students with disabilities, as observers and scorers of special education teachers' classroom performance is extremely limited. Lawson and Cruz (2017) conducted a small study in which school administrators and peers were asked to score special education teachers' video-recorded lessons using seven rubric items that reflected domains of special education teachers' expected teaching skills (e.g., sequencing, scaffolding, student practice and review, and skill development). The authors found that the school administrators who did not possess licensure in special education and did not have experience teaching students with disabilities demonstrated greater agreement in scores when rating teachers on rubric items that reflected instructional strategies that might be expected of all teachers (e.g., articulating a lesson objective). However, they were less reliable when scoring on items that were arguably unique to special education instruction (e.g., instruction that is focused on essential concepts, strategies, and skills with an emphasis on repeated practice). In addition, peer raters, who were experienced special education teachers, were more reliable raters overall than the school administrators, which suggests that administrators may need training and calibration to ensure agreement on scores for special education teachers' observations and evaluations.

School administrators may also encounter limitations in observing and evaluating special education teachers when using observation instruments that were designed for the general education teacher pop- ulation. In a national survey of state- and districtlevel administrators, $85.6 \%$ of respondents reported using the same observation protocol for all teachers including special educators, but administrators reported the need to make modifications when evaluating special education instruction (Holdheide et al., 2010). Some researchers have compared rubric items included in commonly used instruments, such as the Framework for Teaching (FFT) Evaluation Instrument (Danielson, 2011), with research-validated instructional strategies expected of special educators and found that the instruments may not be an appropriate match to special educators' expected teaching skills (Jones \& Brownell, 2013).

Information gathered from classroom observations and other performance data should be used to provide teachers with clear and specific feedback, which has been shown to lead to substantial gains in students' achievement (e.g., Kane \& Staiger, 2012; Taylor \& Tyler, 2011). However, research suggests that the feedback process may be more effective when administrators possess knowledge of a teacher's specific discipline. Tuytens and Devos (2011) found that a teacher's perception of the utility of feedback - determined through a belief regarding the evaluator's knowledge of relevant content-impacted the undertaking of professional learning activities to improve practice. Lochmiller (2016) found that when providing feedback to teachers, administrators often drew from their own experiences as classroom teachers; if the administrator's subject subculture - formed from his or her own prior teaching experience - was not perceived as relevant, the teacher receiving feedback would instead turn to colleagues for more support. Glowacki and Hackmann (2016) found that elementary principals reported a higher skill/comfort level when providing feedback to general education teachers than special education teachers, and principals with special education certification rated their skills in providing feedback more highly than those without a special education certification. The aforementioned studies suggest that administrators who do not have a background in special education, and, thus, do not share the same subculture as their special education teachers, may require additional support in better understanding how to provide feedback specific to teaching students with disabilities.

\section{School Administrator Training and Preparation}

Evaluation in the broader sense encompasses making sense of data from a variety of sources, including classroom observations, to determine a summary judgment of a teacher's level of quality and efficacy. Training related to teacher evaluation can occur 
during school administrators' personnel preparation programs, though the body of research on administrator preparation is limited. Hess and Kelly (2007) investigated how training programs are preparing principals for the challenges of managing personnel by examining 210 syllabi across 31 personnel preparation programs. The authors found that the preparation programs approached personnel management with little attention to training new principals to hire, evaluate, and reward employees, and a considerable percentage of the time related to evaluation was focused on procedural questions (e.g., "what's due when" in the cycles of supervision) and supporting problematic staff.

Duncan, Range, and Scherz (2011) surveyed principals in Wyoming regarding their perceptions of the strengths and deficits of their preparation programs. The principals commonly rated supervision and evaluation as a deficit area, and they reported feeling that they were not prepared to meet those demands. The principals also indicated that they needed more support early in their careers, and there were significant differences in the amount of support required by beginning principals and the amount of professional development received through the district. In a survey of current principals in Mississippi, Alabama, Arkansas, and Louisiana, Styron and LeMire (2009) found that respondents reported agreement that their preparation program had prepared them for their current position, but nearly half of respondents indicated some form of disagreement that their preparation program had prepared them for tasks pertaining to special populations. The authors suggested a deficiency in preparation programs related to developing principals' supervisory and support strategies related to differentiated instruction.

The Council for Exceptional Children's (CEC, 2013) position on special education teacher evaluation is that evaluators should have knowledge of special education teaching and be appropriately trained in effective evaluation practices as they apply specifically to special educators. Steinbrecher et al. (2015) conducted a qualitative study examining school administrators' knowledge of special education, including the skills, knowledge, and dispositions expected within a special education service delivery environment. They found that administrators tended to have limited knowledge of the full range of the CEC preparation standards for special education teachers, especially as they relate to the use of evidence-based practices to support students with disabilities. In addition, though administrators reported that evidence-based practices and collaborative efforts were important to the role of the special education teacher, few were able to elaborate on what those skills looked like in practice.

Though research suggests that a lack of training may impact administrators' feelings of preparedness and efficacy in performing special education teacher evaluations, years of experience may be an important variable to consider when examining school administrators in their roles as evaluators. In a qualitative study of principals who did not have a background in special education, Lawson and Knollman (2017) found that the principals received very little training related to teacher evaluation and no training related to evaluating special education teachers, but the principals reported feelings of confidence due to years of experience observing special education teachers in classroom settings. The principals believed that observations over many years enabled them to gain information regarding special education teachers' instructional practices, and, though additional training would have proved valuable, they felt that their onthe-job experience was integral to developing their skills and efficacy as evaluators of all teachers.

\section{Conceptual Framework and Purpose of the Study}

The framework for the current study was the concept of the school administrator as a manager of personnel (Hess \& Kelly, 2007). As managers of personnel, principals and other instructional leaders are responsible for collecting data on teacher performance through classroom observations and using that data to make high-stakes evaluative decisions that impact the teacher workforce under the leader's purview (Goldring et al., 2015; Grissom \& Loeb, 2009). This study focused on school administrators as managers of their special education teachers--a subpopulation of personnel that school administrators are often tasked with observing and evaluating. Prior research suggests that administrators do not receive adequate preparation for evaluating teachers in general (e.g., Hess \& Kelly, 2007), and there is no existing research on administrator preparation and training related specifically to evaluating special education teachers. Therefore, this study sought to determine the training administrators receive during preparation programs in addition to training that a school district may provide to determine the extent to which administrators are trained to perform functions of the evaluative process for their special education teachers. Furthermore, we were interested in exploring any knowledge and supports administrators reported needing to improve evaluations of their special education teachers. This exploration served a pragmatic purpose, in that it lends itself to potential solutions and practical application, espe- 
cially for educational leaders seeking to improve the evaluative process. Additionally, this study explored administrators' self-efficacy in performing their job duties related to evaluating special education teachers, which was operationalized as confidence in performing the assigned tasks. Glowacki and Hackmann (2016) explored elementary principals' reported skills and comfort level related to providing feedback to special education teachers. The current study was interested in examining how confident administrators of all levels felt in their ability to evaluate special education teachers, including observing teachers, determining a summary judgment, and providing feedback on classroom performance. Finally, research suggests that years of experience (Lawson \& Knollman, 2017) and background in special education teaching (Glowacki \& Hackmann, 2016) may be related to administrators' feelings of confidence; therefore, this study examined whether variables such as years of experience and background in special education teaching were associated with an increase in feelings of confidence in evaluating special education teachers. Using a survey design, this study addressed three broad research questions: (a) What is the quantity and perceived quality of training school administrators receive, both at their school districts and through personnel preparation programs, to conduct evaluations of special education teachers? (b) What knowledge and supports do school administrators believe they need in order to provide an accurate, fair, and meaningful evaluation of a special education teacher on their school site? (c) How do background experience and years of experience relate to school administrators' feelings of confidence in performing special education teacher evaluations?

\section{Method}

\section{Participants}

A total of 929 California school administrators participated in the study. A list of administrators and corresponding email addresses for all active public schools, including charter schools, was obtained from the California Department of Education's publicly accessible database. We accessed the database (updated daily at 5:00 am) in April of 2017 and disseminated an electronic survey via email to all 10,504 school administrators with available email addresses on the list of active schools. As the database only includes the primary administrator for each school (e.g., the principal), the authors also disseminated the survey to other school administrators or leaders (e.g., assistant principals or instructional deans) responsible for teacher evaluations who were part of their professional networks in California. This resulted in an additional 17 school administrators who received the electronic survey via email. From a total of 10,521 potential respondents, 342 emails were returned as undeliverable. This resulted in successful delivery of the electronic survey to 10,179 school leaders. The total of 929 survey respondents reflects a $9 \%$ response rate.

As displayed in Table 1, the survey sample was primarily composed of principals and charter school directors. A small number of respondents were assistant/vice principals or deans, and the remainder of the sample comprised various district-level leaders, including coordinators, directors, assistant superintendents, superintendents, a county office administrator, and a special education local plan area director. The majority of respondents were assigned to the elementary level $(51.2 \%)$ and were not credentialed in special education teaching (88.1\%).

\section{Survey Instrument}

Drawing from the research literature, discussions with school administrators, and the authors' own experiences within schools, the study's authors wrote survey items that reflected the primary aims of the study, which were to determine school administrators' training and support needs related to evaluating special education teachers. The first section of the survey asked administrators to provide information about themselves, including their current assignment (e.g., principal, assistant principal), level of assignment (e.g., elementary, middle), years of experience evaluating general and special education teachers, and whether or not they had ever held a special education teaching credential. The second section of the survey asked administrators to report information about the teacher evaluation system of their school or district, including possible components of the system, as identified by Holdheide et al. (2010). The third section focused on the quantity and perceived quality (in terms of usefulness for informing practice) of the training that school administrators received related to teacher evaluation. The participants were asked about the following: (a) training received from their personnel preparation programs related to evaluating general and special education teachers, (b) the number of days of training received annually from the school district related to evaluating general and special education teachers, (c) the perceived usefulness of training received, and (d) whether the school administrator felt they needed more training.

The final section of the survey asked administrators about needed support and knowledge for the purpose of evaluating special education teachers and their feelings of confidence related to teacher evalua- 
Table 1

Demographic Data of the Study

\begin{tabular}{lcc}
\hline Participant Demographic & $n$ & $\%$ \\
\hline Assignment & 827 & 89.0 \\
Principal or Charter School Director & 34 & 3.7 \\
Assistant/Vice Principal or Dean & 68 & 7.3 \\
District-level Leader (e.g., coordinator, director) & & 51.2 \\
Level of Assignment & 472 & 15.5 \\
Elementary & 143 & 17.2 \\
Middle or Junior High & 159 & 6.2 \\
High School & 57 & 2.4 \\
K/TK-8, 1-8, and 3-8 & 22 & 0.5 \\
K/TK-12 & 5 & 5.6 \\
6 through 12 & 52 & 0.9 \\
District & 8 & 0.4 \\
18-22 (adult education) & 5 & \\
Preschool or TK only & 4 & 88.1 \\
Credentialed in Special Education Teaching & & 11.9 \\
No & 815 & \\
Yes & 110 & \\
\hline
\end{tabular}

tion. Items in this section addressed the following: (a) whether the administrators needed more support from their school district in order to better evaluate special education teachers, (b) the type of support needed, (c) the type of special education-related knowledge needed to better inform the evaluation of special education teachers, (d) feelings of confidence in their ability to evaluate general education teachers, and (e) feelings of confidence in their ability to evaluate special education teachers. The survey items used a variety of response formats, including categorical checklists, dichotomous yes/no options, and 3-, 4-, and 5-point Likert scales. The Likert-type items included scales from strongly disagree to strongly agree, not at all confident to extremely confident, and not at all useful to very useful. Respondents were also provided with space to provide any additional information and/or explain any of their responses.

This study's authors wrote an initial 58 survey items; each item was reviewed and discussed for inclusion in the final instrument. After revisions, a pilot instrument of 27 items was created and tested with two focus groups: one in Northern California and one in Southern California. The pilot instrument was first tested with the Northern California focus group, which consisted of a convenience sample of one principal and four assistant principals. The focus group completed the electronic survey independently, and two of this study's authors convened the group to discuss item interpretation and clarity. After receiving feedback, items were revised, and one item was eliminated, resulting in a 26-item survey. The revised survey was tested with the Southern California focus group, which consisted of a convenience sample of one principal and five assistant principals. The same procedures were followed with the second focus group, and the survey was revised according to feedback received. All focus group members received a \$10 Amazon gift card for their participation. Pilot group data were not included in the final analysis. The final survey included 26 items and took approximately five minutes to complete.

\section{Procedure}

In April of 2017, potential respondents were emailed an anonymous link to complete the survey via Qualtrics. The email also included information about the study and informed participants that the first 50 respondents would receive a \$10 Amazon gift card. 
Upon clicking the link included in the email, participants were directed to the implied consent page, which informed participants of the study's purpose, provided contact information for additional information, and asked participants to indicate that they were over 18 years of age and a current school administrator. No personally identifying information was collected. At the end of the survey, respondents were redirected to a separate URL page that asked for their name and email address should they wish to receive a $\$ 10$ Amazon gift card for their participation. This information was in no way attached to the survey data. The first 50 respondents to complete the survey and provide contact information received a $\$ 10$ Amazon gift card via email. The survey was distributed once to potential respondents and the link remained open during a four-week period from April of 2017 to May of 2017.

\section{Data Analysis}

The response data were analyzed using statistical techniques that are prevalent in survey methodology. To investigate research questions (a) and (b), we considered various descriptive statistics related to quantity of training, quality of training, and needed knowledge and supports. To investigate research question (c), we performed $t$-tests and a series of polyserial correlations among respondent background, years of experience, and confidence. All analyses were carried out using the $p$ sych package (Revelle, 2017) in the $R$ statistical computing environment ( $R$ Core Team, 2017).

\section{Results}

The survey data are described and displayed below. Some respondents did not complete the entire survey, and some survey questions were posed only to respondents who responded in a particular way to a prior question. In the cases of items with missing data, results are reported based on those respondents who completed the relevant item.

The participants were asked to report whether they currently held or had ever held a special education teaching credential, their years of experience evaluating all teachers, and their years of experience evaluating special education teachers. Of the 925 participants who provided valid data, $88.1 \%$ reported never having held a special education teaching credential, and $11.9 \%$ had held a special education teaching credential at some point during their career. The administrators' years of experience evaluating teachers ranged from 0 years $(n=1)$ to 39 years $(n=1)$, with a mean of 10.64 years and a standard deviation of 6.73 years. The administrators' years of experience evalu- ating special education teachers ranged from 0 years $(n=30)$ to 39 years $(n=1)$, with a mean of 9.75 years and a standard deviation of 6.80 years.

The second section of the survey asked respondents about their district or school evaluation system; this information can be seen in Table 2. Participants were asked to indicate which of 10 possible components were included in their evaluation systems. The most frequently identified component was observation protocols (95.2\%) followed by goal-driven professional development (55.2\%). Participants also frequently reported that classroom artifacts $(39.1 \%)$, selfreport measures $(33.0 \%)$, and criterion-referenced or curriculum-based measures $(22.2 \%)$ were included. When asked whether a separate or modified evaluation system was allowed for special education teachers, $84.7 \%$ responded no. Participants were also asked whether they agreed that the evaluation system helps teachers grow and improve their practice: $10.5 \%$ strongly agreed, $53.3 \%$ somewhat agreed, $14.0 \%$ neither agreed nor disagreed, $15.7 \%$ somewhat disagreed, and $6.5 \%$ strongly disagreed.

Participants were asked to report training they received through their personnel preparation programs for evaluating both teachers generally and special education teachers specifically; results can be seen in Figure 1. Regarding teacher evaluation in general, approximately one eighth of respondents received an entire class of training and nearly half received a partial class; however, over one quarter of respondents received no training in teacher evaluation. The 14 participants who responded other specified that their training occurred over several weeks, over several courses, or through a coach or mentoring. Regarding special education teacher evaluation in particular, nearly three quarters of the respondents reported receiving no training in their personnel preparation programs, while most of the remaining quarter reported receiving training as part of a class. In addition, two participants responded other and specified that training specific to evaluating special education teachers occurred through mentoring or was addressed within the broader topic of evaluating all teachers.

Those who received training in the aforementioned areas were asked to rate the usefulness of that training in terms of informing their evaluation practices; results are displayed in Figure 3. Overall, the results were quite similar regardless of whether the training focused on general or special education teachers or whether that training was part of the personnel preparation program or provided annually by the school district. More specifically, across all four areas, 
Table 2

Evaluation System Information

\begin{tabular}{lcc}
\hline Survey Items & $n$ & $\%$ \\
\hline Components of the Evaluation System & 884 & 95.2 \\
Observation protocols & 363 & 39.1 \\
Classroom artifacts & 124 & 13.3 \\
Teacher portfolio & 307 & 33.0 \\
Self-report measures (teacher survey/checklists) & 122 & 13.1 \\
Standardized achievement scores (e.g., value added) & 70 & 7.5 \\
Student perceptual surveys & 77 & 8.3 \\
Parent/family surveys & 206 & 22.2 \\
Criterion-referenced or curriculum-based measures & 513 & 55.2 \\
Goal-driven professional development & 116 & 12.5 \\
Peer review/evaluation & & 84.7 \\
Separate or modified system for special education teachers & 780 & 15.3 \\
No & 141 & \\
Yes & & \\
\hline
\end{tabular}

approximately $60-65 \%$ of survey respondents found their teacher evaluation training to be somewhat useful; approximately $17-22 \%$ found their training to be very useful; and the remaining $16-18 \%$ rated their training as not at all useful.

When asked if they felt they needed more training related to evaluating special education teachers, $59.8 \%$ $(n=544)$ of the school administrators responded yes and $40.2 \%(n=366)$ responded no. When asked if they felt they needed more support related to evaluating

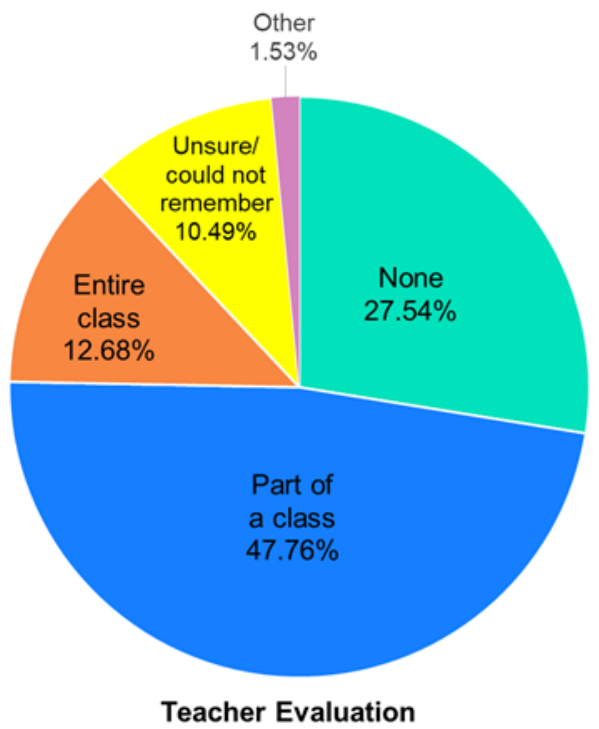

special education teachers, $61.0 \%(n=552)$ responded yes and $39.0 \%(n=353)$ responded no. For those who indicated that they needed more support, they were asked to select the types of support that would better enable them to evaluate special education teachers (respondents could select more than one type); $47.4 \%$ $(n=440)$ reported needing professional development, $39.8 \%(n=370)$ reported needing consultation with special education administrators, and $36.1 \%(n=335)$ wanted input from special education teachers. Twenty-two participants selected other as a response, and

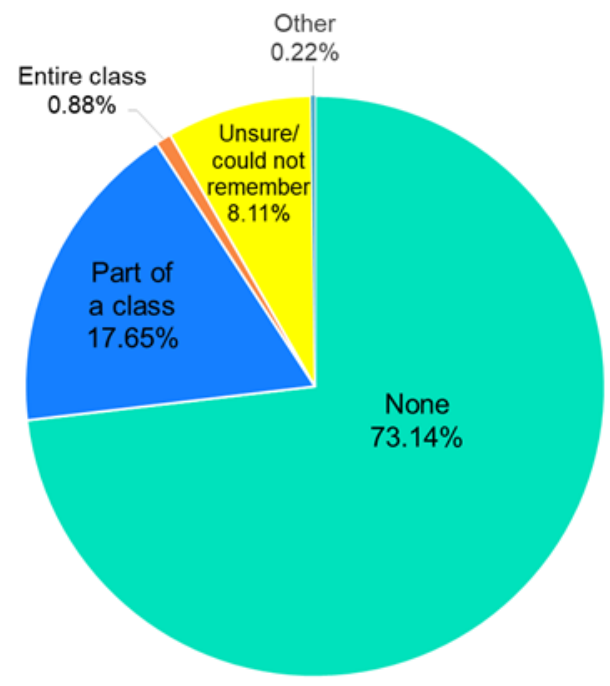

Special Education Teacher Evaluation

Figure 1. Training that school administrators received in their personnel preparatory program. 


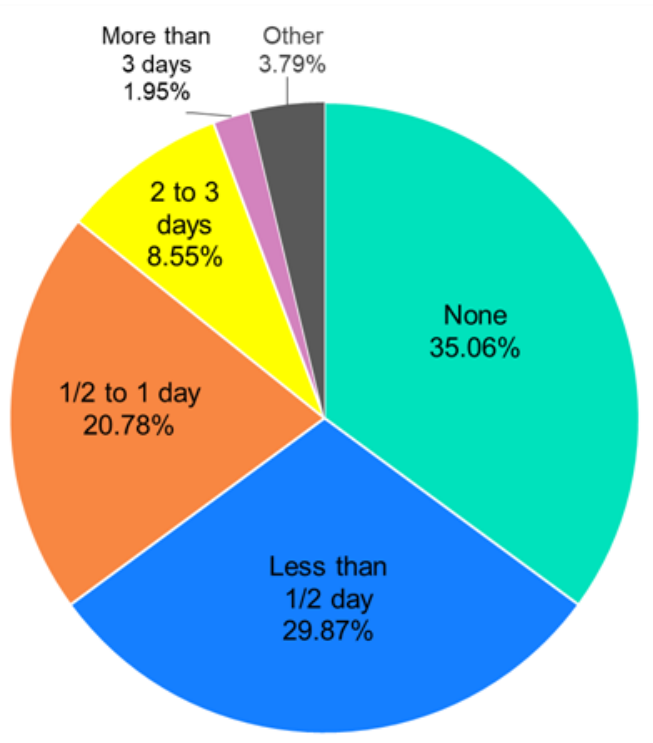

Teacher Evaluation

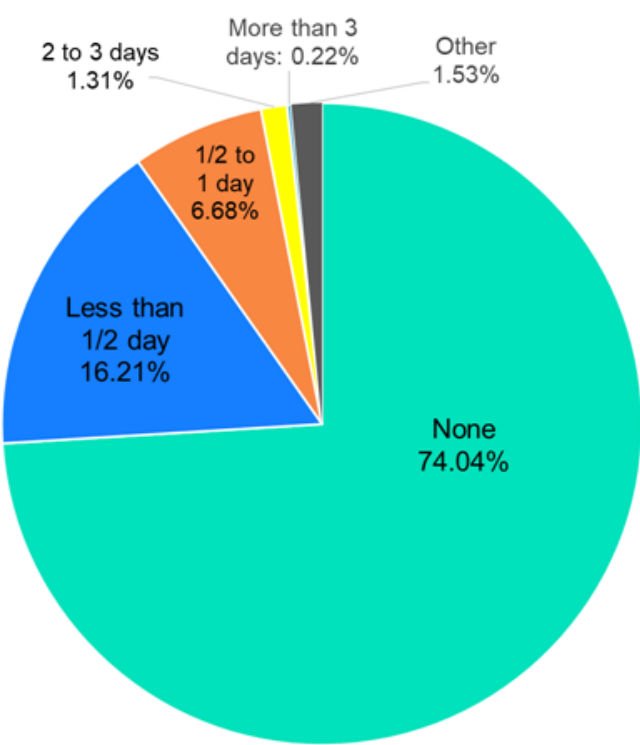

Special Education Teacher Evaluation

Figure 2. Training that school administrators received annually from their school district.

almost all of those respondents indicated needing evaluation tools that were better aligned with the special education teachers' expected teaching skills and instructional settings.

Participants were also asked about the type of knowledge they felt they needed to better evaluate special education teachers. The school administrators reported needing more information on the following: evidence-based practices for teaching students with disabilities $(66.8 \%, n=621)$, behavior management techniques $(44.2 \%, n=411)$, disability-specific information $(46.7 \%, n=434)$, and how severity of disability impacts classroom performance $(45.7 \%, n=425)$. Forty-eight participants indicated other types of knowledge and included the following responses: information related to special education law, components of the Individualized Education Program (IEP), and differentiated instructional practices.

We asked participants to indicate their feelings of confidence related to evaluating all teachers and specifically special education teachers on a scale from 1 (not at all confident) to 5 (extremely confident). We conducted a series of analyses to determine how the participants' background and experience related to feelings of confidence. First, to determine if there were differences in feelings of confidence when administrators evaluated general education versus special education teachers, we conducted a paired-samples $t$-test; results indicated that administrators were significantly more confident when evaluating general education teachers $(M=4.31, S D=.74)$ than when evaluating special education teachers $(M=3.71, S D=.87), t(899)$
$=20.329, p<.001$. The mean difference was .599 , with a $95 \%$ confidence interval from .541 to .657 , indicating that along the 5-point rating scale, administrators were just over half a point more confident when evaluating general rather than special education teachers.

Regarding confidence in evaluating special education teachers, an independent-samples $t$-test revealed a significant difference between administrators who held (previously or currently) a special education teaching credential $(M=1.68, S D=.64)$ and those who $\operatorname{did} \operatorname{not}(M=2.37, S D=.86), t(165.58)=-10.153, p$ $<.001$. The mean difference was -.697 , with a $95 \%$ confidence interval from -.833 to -.562 , indicating that along the 5-point rating scale, administrators with special education teaching credentials were approximately .70 points more confident than administrators without special education teaching credentials when evaluating special education teachers.

In this study, we sought to determine whether there was an association between school administrators' years of experience evaluating all teachers and reported feelings of confidence in evaluating special education teachers. Results revealed a significant polyserial correlation between years of experience and feelings of confidence evaluating special education teachers (on a scale from $1=$ not at all confident to $5=$ extremely confident), $\rho=.317, p<.001$. In other words, evaluators who had more experience with teacher evaluation generally were more likely to feel greater confidence when evaluating special education teachers. For example, reports of feeling extremely confident were observed far more frequently among evaluators 

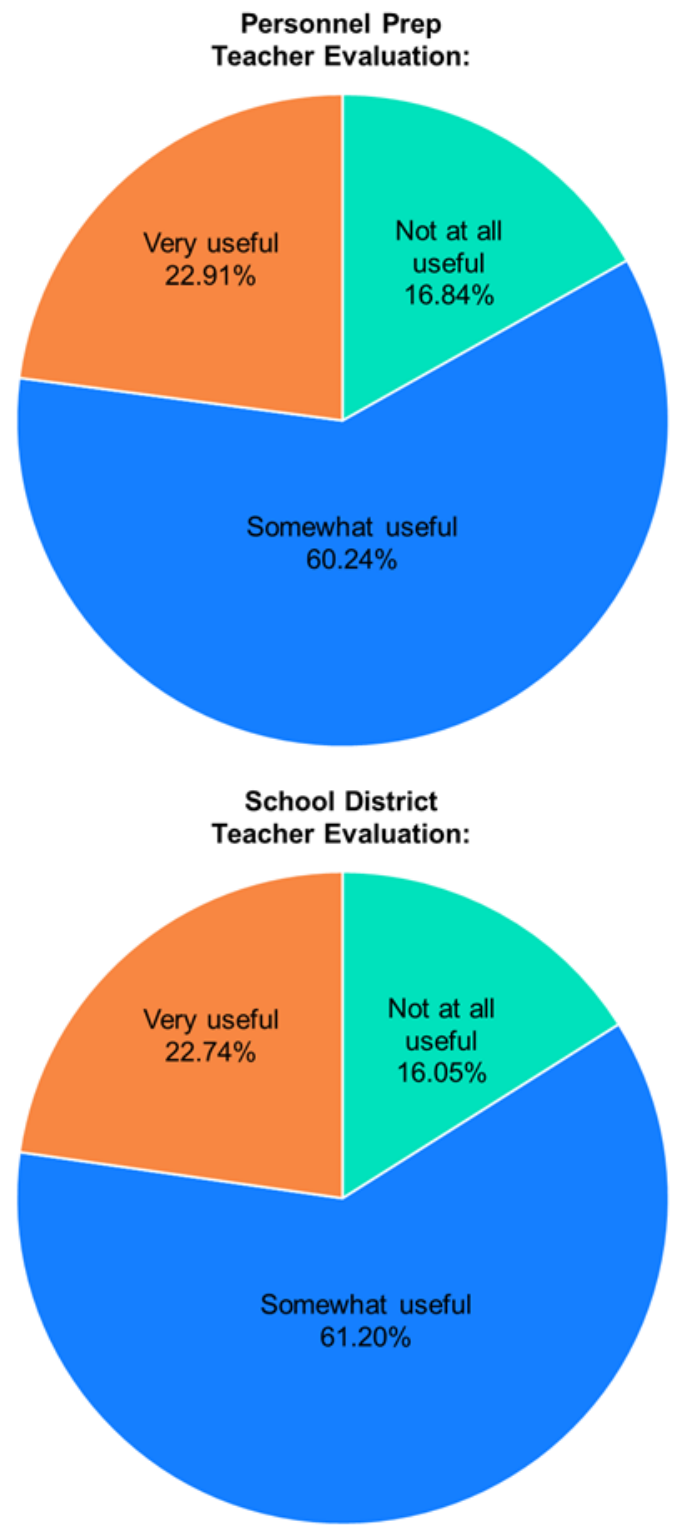

Personnel Prep

Special Education Teacher Evaluation:

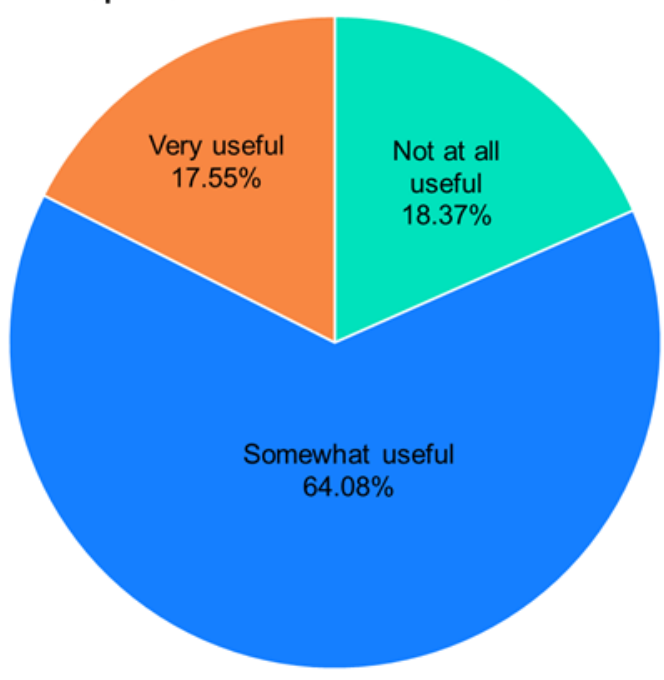

School District

Special Education Teacher Evaluation:

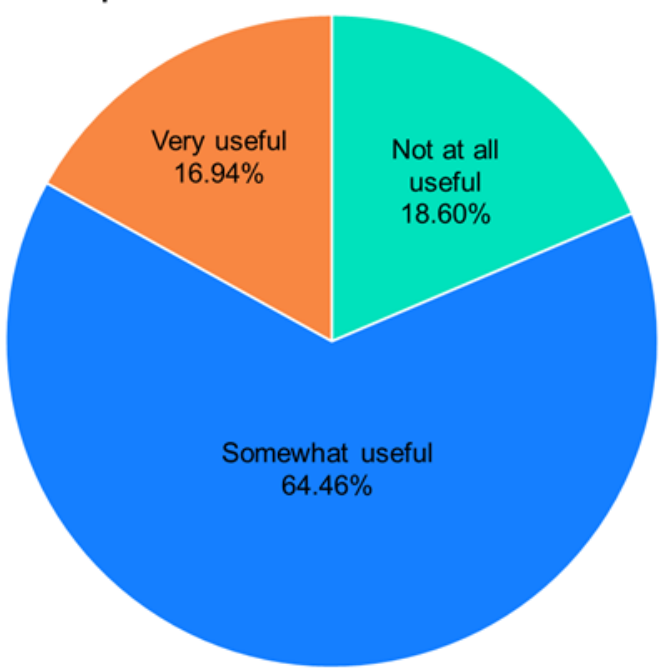

Figure 3. Respondents' perceptions of the usefulness of training received.

were observed far more frequently among evaluators with more experience. Further, among those with fewer than five years of experience, nearly one in eight evaluators reported feeling slightly or not at all confident in evaluating special education teachers. This rate was approximately 1 in 14 among administrators with 5 to 10 years of experience, and 1 in 60 among evaluators with 15 to 20 years of experience.

We also sought to determine how having a special education teaching credential and years of experience evaluating special education teachers might impact school administrators' feelings of confidence in evaluating special education teachers. Among the $N=110$ administrators who held a special education teaching credential, there was a trending significant polyserial correlation between years of experience with special education teacher evaluation and feelings of confidence evaluating teachers with special education credentials, $\rho=.183, p=.083$. Administrators with special education teaching credentials who had less special education teacher evaluation experience were just as likely as those with many years of experience to feel confident when evaluating special education teachers. Table 3 displays the percentage of administrators with special education teaching credentials at a given experience level who selected each of the five confidence options. Note that among the special education credentialed administrators, the slightly and not at all options were never selected. Further, all administrators with a special education teaching credential and 15 or 
Table 3. Distribution of Responses to the Survey Question "To what extent do you feel confident in your ability to evaluate teachers with special education credentials on your school site?" Among Administrators with and without Special Education Teaching Credentials with Varying Levels of Experience Evaluating SPED Teachers

\begin{tabular}{lccccccc}
\hline Years & $\begin{array}{c}\text { SPED } \\
\text { Cred }\end{array}$ & $n$ & Notat all & Slightly & Moderately & Very & Extremely \\
\hline$<5$ & Yes & 29 & - & - & 9.09 & 48.48 & 42.42 \\
& No & 280 & 2.97 & 12.64 & 49.44 & 27.88 & 7.06 \\
\multirow{2}{*}{$5-10$} & Yes & 28 & - & - & 18.52 & 44.44 & 37.04 \\
& No & 213 & - & 5.37 & 37.56 & 42.44 & 14.63 \\
\multirow{2}{*}{$10-15$} & Yes & 29 & - & - & 7.41 & 59.26 & 33.33 \\
& No & 176 & - & 2.89 & 34.10 & 41.62 & 21.39 \\
$15-20$ & $Y e s$ & 14 & - & - & - & 40.00 & 60.00 \\
& No & 100 & - & 1.03 & 18.56 & 53.61 & 26.80 \\
$>20$ & Yes & 10 & - & - & - & 50.00 & 50.00 \\
& No & 47 & - & - & 18.18 & 50.00 & 31.82 \\
\hline
\end{tabular}

Note. $N_{Y e s}=110 ; N_{N o}=819$. Response values are percentages.

more years of experience felt very or extremely confident in their evaluations of special education teachers.

Among the $N=819$ administrators who did not hold a special education teaching credential, there was a significant polyserial correlation between years of experience with special education teacher evaluation and feelings of confidence evaluating teachers with special education credentials (on a scale from $1=$ not at all confident to $5=$ extremely confident), $\rho=-361, p$ $<.001$. In other words, administrators without special education teaching credentials who had more special education teacher evaluation experience were more likely than those with less experience to feel confident when evaluating special education teachers. Table 3 displays the percentage of administrators without special education teaching credentials at a given experience level who selected each of the five confidence options. Relative to the administrators with special education teaching credentials, the non-special education credentialed administrators tended to endorse the not at all and slightly response options, especially when they were less experienced. The rightmost column of Table 3 also reveals that, regardless of experience, the administrators with special education teaching credentials reported feeling extremely confident far more than did their non-special education credentialed counterparts. Further, these results indicate that the confidence of non-special education creden- tialed administrators may increase over time; the percentage of not at all and slightly responses decreased with experience, while the percentage of very and extremely responses increased with experience.

\section{Discussion}

Consistent with prior research (Glowacki \& Hackmann, 2016; Jones \& Brownell, 2013), most school administrators in this sample did not hold special education teaching credentials at any point in their careers, indicating that their background and training related to instructional practices came predominately from general education. Also consistent with prior research (Holdheide et al., 2010), 95\% of respondents in this sample indicated observations as a component of their teacher evaluation system, and for the majority of participants, the same evaluation system was applied to both general and special education teachers. Therefore, results from this study confirm that many school administrators use the same system, which includes classroom observations and relevant rubrics, to evaluate both their general and special education teachers, but most of the school administrators have not had formal training in teaching students with disabilities. This finding highlights the need to provide additional support for school administrators when evaluating the classroom practices of special education teachers, especially given findings from prior research that observation instruments may not be an appropriate match 
to special educators' expected teaching skills (Jones \& Brownell, 2013) and that school administrators may be less reliable scorers when evaluating instructional practices arguably unique to special education (Lawson \& Cruz, 2017). Furthermore, administrators without formal training in teaching students with disabilities may be unable to appropriately modify their observation systems to accurately reflect special education teachers' expected instructional practices.

Though school administrators are tasked with evaluating personnel, a large number of the administrators in this study did not receive training related to teacher evaluation either from their personnel preparation programs or from their school district. Twentyseven percent of the administrators reported no training from their personnel preparation program, and $34.9 \%$ reported no training from their school district. For school administrators who did not receive training from either a personnel preparation program or through the school district, they did not receive any preparation for the role of teacher evaluator. Related to special education teacher evaluations, the percentage of school administrators in this study who did not receive training was considerably higher: $71.8 \%$ received no training in their personnel preparation program and $73.8 \%$ received no training from the school district.

Overall, the majority of school administrators in this sample did not receive training from their personnel preparation program or annually from their school district related to evaluating special education teachers. The implications of the lack of training are yet unknown, though it may be problematic if school administrators are unfamiliar with the roles, responsibilities, and instructional practices unique to a special educator, as Steinbrecher et al. (2015) suggest. Without a background in special education and training on evaluating special education teachers, the reliability of observation scores may be undermined (Jones \& Brownell, 2013). The administrators may make unsystematic modifications to existing evaluation instruments (Holdheide et al., 2010), rendering them less reliable and valid, and special education teachers may not perceive utility in the feedback they receive.

For respondents who did receive training, most (between 60 and 65\%) reported the training to be somewhat useful for informing practice. Respondents were fairly consistent in their rating of perceived usefulness across all types of training, including training received from both the personnel preparation program and the school district. More research is necessary to determine aspects of training that better inform school administrators' practices, both in the are- as of teacher evaluation generally and special education teacher evaluation specifically. However, providing training alone is insufficient if school administrators do not find the training to be helpful in terms of strengthening their skills as an evaluator.

The majority of administrators in this study (approximately 60\%) reported needing more training and support for evaluating special education teachers. The administrators believed they would benefit from professional development, consultation with special education administrators, and input from special education teachers. Several of the school administrators also noted in their comments that they needed evaluation tools that were better aligned to a special education teacher's roles, responsibilities, and expected teaching skills. Nearly $70 \%$ of administrators reported wanting more information on evidence-based practices for teaching students with disabilities. There is a robust body of literature on effective strategies for teaching students with disabilities, including the recently published High-Leverage Practices for Special Education Teachers (McLeskey et al., 2017). With a wealth of available information, preparation programs and districts could consider how to incorporate training on theses specific practices to assist school administrators in observing, evaluating, and providing feedback to special education teachers.

Overall, participants reported feeling more confident evaluating general education teachers than special education teachers, and administrators who had held special education teaching credentials were more confident in their ability to evaluate special education teachers than their peers. For those administrators without a background in special education, more years of experience evaluating special education teachers was associated with greater feelings of confidence evaluating special education teachers. Interestingly, years of experience was not related to feelings of confidence for administrators who had held a special education teaching credential. For these school administrators, they were likely to feel confident evaluating special education teachers whether they had few or many years of experience with special education teacher evaluation. Similar to Lochmiller's (2016) discussion of content subculture, the administrators with a background in special education may share the same "subculture" as the special education teachers they evaluate, making the evaluative process one in which they feel more confident performing. For administrators without a background in special education, their confidence increased with years of experience, indicating that on-the-job experience can be its own training ground, and repeated visits to class- 
rooms and experiences with teachers of students with disabilities may prove valuable in informing their evaluative practices. The implication of this finding is also that district training and support should especially be provided in the early years of administration, which corroborates the finding of Duncan et al. (2011) that principals reported needing more support early in their careers.

\section{Limitations}

The demographics of the present study pose a limitation regarding generalizability. The present sample was limited to the state of California, and it is unclear whether these results are generalizable to other states or regions within the United States that may include different preparation programs, professional development opportunities, training practices, and evaluation systems. The generalizability of this study's findings should be assessed in the future by replicating this study using a nationwide survey. In addition, though the respondent sample was quite large, it represents only a $9 \%$ response rate. We are uncertain whether the responders differed from the population in ways that would bias the results, though research indicates that the distributions of substantive responses are unrelated or weakly related to response rates (Holbrook, Krosnick, \& Pfent, 2007).

This study is also limited in that it includes only a self-report measure. Participants may not have accurately recalled the amount of training they received, and, for some participants, the training may have taken place many years prior. Future studies could include obtaining more specific information from personnel preparation programs and districts regarding training. Future studies could also include qualitative components to further expound on administrators' experiences related to observing, evaluating, and providing feedback to their special education teachers.

\section{Future Directions}

Though participants' comments were not evaluated qualitatively for this study, it should be noted that many respondents commented on the need for evaluation instruments that better aligned with special education teachers' roles and responsibilities. Future research should consider how evaluation systems can include components that capture the range of responsibilities required of a special education teacher (e.g., case management and collaboration with other practitioners) and that especially include observation protocols that reflect special education teachers' evidencebased instructional practices. Use of observation tools that represent evidence-based practices in the field could greatly improve feedback that special education teachers receive and, thus, improve their practice.

Additionally, evaluators, especially those with limited background in special education instructional practices, would benefit from increased training opportunities. Future research should examine the ways in which school districts could calibrate and coordinate teacher evaluators at school sites in order to provide effective training regarding teaching practices that are specific to teaching students with disabilities. Research around different types of professional development and the quantity needed to help administrators effectively observe, evaluate, and provide feedback to special education teachers should be explored.

\section{References}

Council for Exceptional Children. (2013). The Council for Exceptional Children's position on special education teacher evaluation. Teaching Exceptional Children, 45, 73-76.

Danielson, C. (2011). The framework for teaching evaluation instrument. Princeton, NJ: The Danielson Group.

Duncan, H., Range, B., \& Scherz, S. (2011). From professional preparation to on-the-job development: What do beginning principals need? International Journal of Educational Leadership Preparation, 6(3), 120.

Every Student Succeeds Act of 2015, Pub. L. No. 114$95 \S 114$ Stat. 1177 (2015-2016).

Glowacki, H., \& Hackmann, D. G. (2016). The effectiveness of special education teacher evaluation processes: Perspectives from elementary principals. Planning and Changing, 47, 191-209.

Goldring, E., Grissom, J. A., Rubin, M., Neumerski, C. M., Cannata, M., Drake, T., \& Schuermann, P. (2015). Make room value added: Principals' human capital decisions and the emergence of observation data. Educational Researcher, 44, 96-104. doi: 10.3102/0013189X15575031

Grissom, J. A., \& Loeb, S. (2009). Triangulating principal effectiveness: How perspectives of parents, teachers, and assistant principals identify the central importance of managerial skills. [Working Paper 35]. Washington, DC: National Center for Analysis of Longitudinal Data in Education Research. Retrieved from https://www.urban.org/sites/ default/files/publication/33316/1001443Triangulating-Principal-Effectiveness-HowPerspectives-of-Parents-Teachers-and-AssistantPrincipals-Identify-the-Central-Importance-ofManagerial-Skills.PDF 
Grissom, J. A., Loeb, S., \& Master, B. (2014). Effective instructional time use for school leaders: Longitudinal evidence from observations of principals. Educational Researcher, 42, 433-444. doi: 10.3102/0013189X13510020

Hess, F. M., \& Kelly, A. P. (2007). Learning to lead: What gets taught in principal-preparation programs. Teachers College Record, 109, 244-274.

Holbrook, A., Krosnick, J. A., \& Pfent, A. (2007). The causes and consequences of response rates in surveys by the news media and government contractor survey research firms. In J. M. Lepkowski, N. C. Tucker, J. M. Brick, E. de Leeuw, L. Japec, P. J., Lavrakas, ...R. L., Sangster (Eds.), Advances in telephone survey methodology (pp. 499-528). Hoboken, NJ: John Wiley \& Sons, Inc.

Holdheide, L. R., Goe, L., Croft, A., \& Reschly, D. J. (2010). Challenges in evaluating special education teachers and English Language Learner specialists. [Research and Policy Brief]. National Comprehensive Center for Teacher Quality. Retrieved from http://files.eric.ed.gov/fulltext/ ED520726.pdf

Jones, N. D., \& Brownell, M. T. (2013). Examining the use of classroom observations in the evaluation of special education teachers. Assessment for Effective Intervention, 39, 112-124. doi: $10.1177 / 1534508413514103$

Kane, T. J., \& Staiger, D. O. (2012). Gathering feedback for teaching: Combining high-quality observations with student surveys and achievement gains. Retrieved from http://www.metproject.org/downloads/ MET_Gathering_Feedback_Research_Paper.pdf

Lawson, J. E., \& Cruz, R. A. (2017). Evaluating special education teachers' classroom performance: Rater reliability at the rubric item level. Teacher Education and Special Education. Advance online publication. doi: 0888406417718250

Lawson, J. E., \& Knollman, G. A. (2017). Evaluating special education teachers: School administrators' perceptions of the process. The Journal of Special Education Leadership, 30(1), 6-18.

Lochmiller, C. R. (2016). Examining administrators' instructional feedback to high school math and science teachers. Educational Administration Quarterly, 52, 75-109. doi: 10.1177/0013161X15616660
McLeskey, J., Barringer, M-D., Billingsley, B., Brownell, M., Jackson, D., Kennedy, M., . . . Ziegler, D. (2017, January). High-leverage practices in special education. Arlington, VA: Council for Exceptional Children \& CEEDAR Center. Retrieved from https://www.researchgate.net/profile/ James_Mcleskeypublication/320948290_High_Lev erage_Practices_for_Special_Education_Teachers/ links/5a044089a6fdcc1c2f5bc809/High-LeveragePractices-for-Special-Education-Teachers.pdf

R Core Team (2017). R: A Language and Environment for Statistical Computing. Vienna, Austria: R Foundation for Statistical Computing. https://www.Rproject.org

Revelle, W. (2017). psych: Procedures for Psychological, Psychometric, and Personality Research (R package version 1.8.4). Evanston, IL: Northwestern University.

Sledge, A., \& Pazey, B. L. (2013). Measuring teacher effectiveness through meaningful evaluation: Can reform models apply to general education and special education teachers? Teacher Education and Special Education, 36, 231-246. doi: 10.1177/0888406413489839

Steinbrecher, T. D., Fix, R., Mahal, S. A., Serna, L., \& McKeown, D. (2015). All you need is patience and flexibility: Administrators' perspectives on special educator knowledge and skills. Journal of Special Education Leadership, 28, 89-102.

Styron, Jr., R. A., \& LeMire, S. D. (2009). Principal preparation programs: Perceptions of high school principals. Journal of College Teaching \& Learning, 6 (6), 51-62.

Taylor, E. S., \& Tyler, J. H. (2011). The effect of evaluation on performance: Evidence from longitudinal student achievement data of mid-career teachers. [Working Paper 16877]. Cambridge, MA: National Bureau of Economic Research. Retrieved from http://www.nber.org/papers/w16877

Tuytens, M., \& Devos, G. (2011). Stimulating professional learning through teacher evaluation: An impossible task for the school leader? Teaching and Teacher Education, 27, 891-899. doi: 10.1016/ j.tate.2011.02.004 